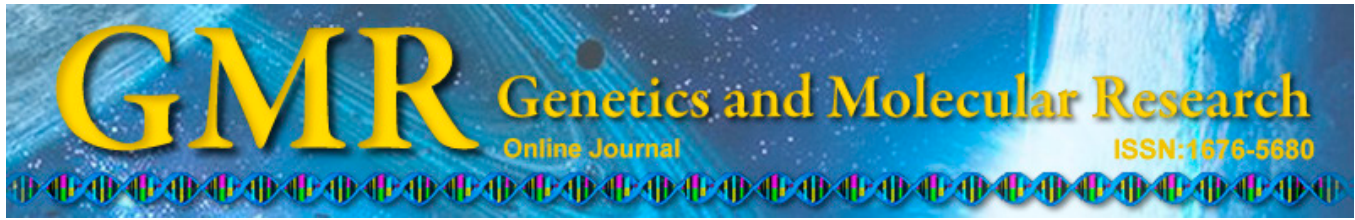

\title{
Cloning of flanking sequence in transgenic plants by restriction site-anchored single- primer polymerase chain reaction
}

\author{
J. Ma, N.N. Wang, S. Ren, Y.P. Fu, S. Lu, Y.P. Wang and P.W. Wang \\ Biotechnology Center of Jilin Agricultural University, Changchun, Jilin, \\ China \\ Corresponding author: P.W. Wang \\ E-mail: davidmedsci@sina.com
}

Genet. Mol. Res. 13 (4): 10556-10561 (2014)

Received January 21, 2014

Accepted May 9, 2014

Published December 12, 2014

DOI http://dx.doi.org/10.4238/2014.December.12.18

\begin{abstract}
Determining the insertion position of an exogenous gene in the target plant genome is one of the main issues in the transgenic plant field. This study introduced a simple, rapid, and accurate method to clone the flanking sequences of the transgenic bar gene as the anchoring gene in the transgenic maize genome using single-primer polymerase chain reaction (PCR). This method was based on the distribution of restriction sites in the maize genome and adopted the single-primer PCR method. Cloning the flanking sequences with the restriction siteanchored single-primer PCR simplified the experimental procedures by about $70 \%$ and reduced the experimental time by more than $80 \%$. In conclusion, the restriction site-anchored single-primer PCR was a simple, rapid method to obtain the unknown flanking sequences in the transgenic plants.
\end{abstract}

Key words: Single-primer polymerase chain reaction; Unknown flanking sequences; Transgenic plants; Restriction sites 


\section{INTRODUCTION}

One of the important issues in the transgenic plant field is determining the integration position of an exogenous gene in the target plant genome or determining the flanking sequences of the inserted gene. Currently, polymerase chain reaction (PCR) techniques are widely used to determine the insertion position of the exogenous gene in the genome. These techniques include adapter-ligation-mediated PCR (Jones and Winistorfer, 1992), thermal asymmetric interlaced PCR (TAIL-PCR) (Liu and Whittier, 1995; Liu et al., 1995; Liu and Chen, 2007), and restriction site extension PCR (Kim et al., 2004; Ji and Braam, 2010); of these, TAIL-PCR is the most commonly used. However, TAIL-PCR requires 3 anchor primers and 4-8 degenerate random primers for the known sequences, and then it obtains the flanking sequences of the known gene through 3 rounds of the TAIL-PCR (Song et al., 2005; Liang et al., 2010). In TAIL-PCR, the primer design is complex, the PCR procedures and operation are complicated, and $8-10 \mathrm{~h}$ should be taken to complete an experiment, making it very timeconsuming. Restriction site extension PCR requires that the genome is digested prior to PCR, and the technique is complicated (Kim et al., 2004; Ji and Braam, 2010).

The arrangement of restriction sites in the plant genome is fixed, and any exogenous gene will carry some restriction sites. For instance, the bar gene carries the salI, $k p n \mathrm{I}$, and sacII sites (Antal et al., 2004). If the exogenous gene is inserted into the genome of the target plant, it will change the original arrangement of restriction sites of the target plant. Then, if we can identify such changes in the arrangement of restriction sites, we can obtain the flanking sequences of the inserted position (Ma et al., 2011a,b, 2012). Based on the above analysis, the principle of this study is shown in Figure 1 using the salI site in the bar gene as an example.

In this study, we used high-generation transgenic maize as the plant material and designed 3 single primers for bar gene-based sequences. Using a 33-cycle single-primer PCR, we obtained the flanking sequences of the bar gene (as the known gene) in the transgenic maize.
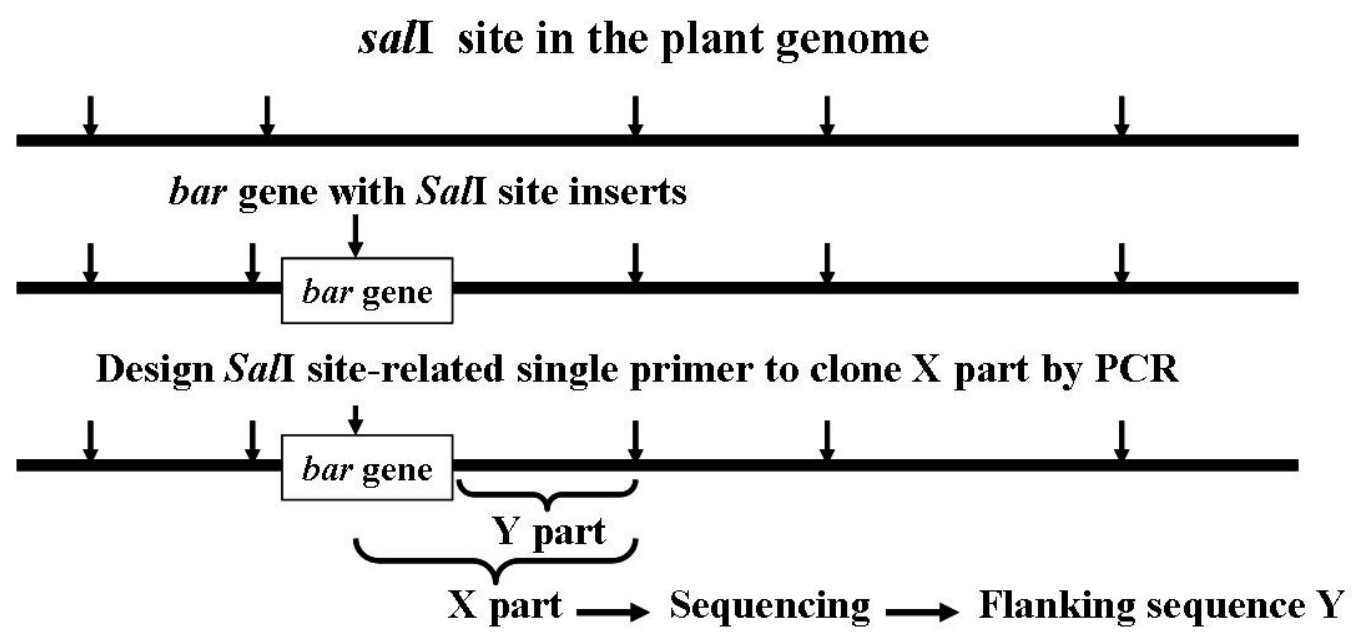

Figure 1. Principle of the study. 


\section{MATERIAL AND METHODS}

\section{Materials}

Genomic DNA was extracted from the bar-transgenic maize that was subjected to the agrobacterium-mediated method using the pCAMBIA3301 vector. Taq DNA polymerase, 10 $\mathrm{mM}$ dNTP, and 10X PCR buffer were purchased from IBM (USA). Agarose was supplied by AMRESCO (USA). The genomic DNA extraction kit and DNA marker were purchased from TaKaRa (China).

\section{Primers}

Three bar-related single primers were designed, their sequences are shown in Table 1, and the positions of these primers in the T-vector are illustrated Figure 2. The method for designing the P1 single primer was as follows. The kpnI restriction site sequence GGTACC $\left(5^{\prime}-3^{\prime}\right)$ in the bar gene was found, and then 11 bases toward the 5'-end were incorporated (5'-TTCAGCCTGCC-3'), forming the P1 primer sequence: 5'-TTCAGCCTGCCGGTACC-3'. This single primer could pair with the bar gene completely, could be used as the anchor primer, and could also be used as a random primer by considering the genomic distribution of restriction sites. The methods for designing the P2 and P3 single primers were the same as the above.

Table 1. Primer information.
\begin{tabular}{llcc}
\hline Primer & Sequence (5'-3') & Length (bp) & Distance from the left T-border (bp) \\
\hline P1 $(k p n I)$ & TTCAGCCTGCCGGTACC & 17 & 334 \\
P2 (sall) & TGGACGGCCGAGTCGAC & 17 & 583 \\
P3 ( sac II) & GATTAGCCCCCCGCGG & 16 & 415 \\
\hline
\end{tabular}

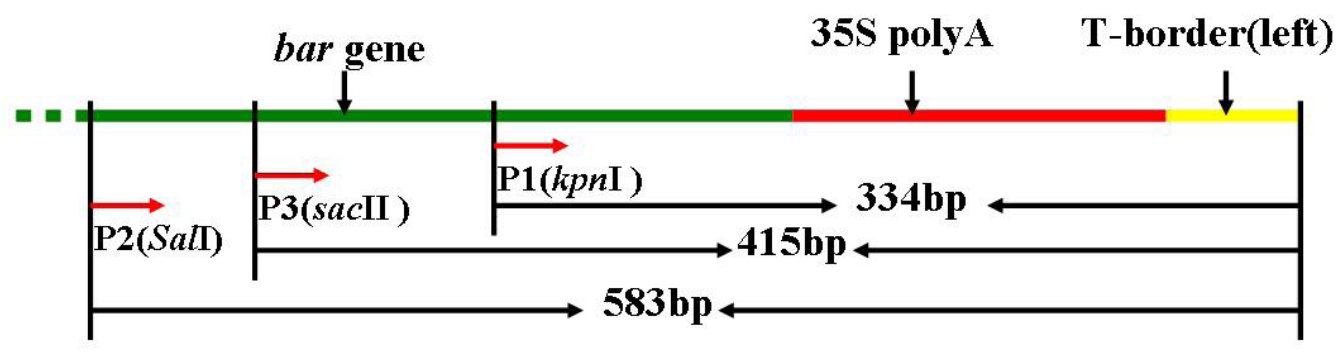

Figure 2. Position of single primers in the T-vector pCAMBIA3301.

\section{PCR procedures and sequencing}

Total DNA was extracted from the plant leaves using the Universal Genomic DNA Extract kit (version 3.0) according to manufacturer instructions (TaKaRa Company). The 50$\mu \mathrm{L}$ reaction mixture for the $\mathrm{P} 1$ single-primer amplification contained $5.0 \mu \mathrm{L} 10 \mathrm{X}$ buffer, $1.0 \mu \mathrm{L}$ $10 \mathrm{mM}$ dNTPs, $1.0 \mu \mathrm{L} 20 \mu \mathrm{M}$ P1 primer, $1.0 \mu \mathrm{L}$ genomic DNA template $(<1 \mu \mathrm{g}), 1.0 \mu \mathrm{L} 2.5$ 
$\mathrm{U} / \mu \mathrm{L}$ Taq DNA Polymerase, and $32 \mu \mathrm{L} \mathrm{ddH}_{2} \mathrm{O}$. The PCR conditions were as follows: $94^{\circ} \mathrm{C}$ for $120 \mathrm{~s} ; 3$ cycles of $94^{\circ} \mathrm{C}$ for $40 \mathrm{~s}, 59^{\circ} \mathrm{C}$ for $30 \mathrm{~s}$, and $72^{\circ} \mathrm{C}$ for $120 \mathrm{~s} ; 30$ cycles of $94^{\circ} \mathrm{C}$ for $40 \mathrm{~s}$ and $68^{\circ} \mathrm{C}$ for $120 \mathrm{~s}$; and $72^{\circ} \mathrm{C}$ for $5 \mathrm{~min}$. The reaction mixture and cycling conditions for the $\mathrm{P} 2$ and P3 single-primer amplifications were the same as those for P1 PCR. Transgenic and nontransgenic plants shared the same PCR procedures. PCR products were separated on $2 \%$ agarose gels. The exclusive bands of the transgenic plants, with lengths that were larger than 314 , 583, and $415 \mathrm{bp}$, were extracted routinely, sequenced, and analyzed by Basic Local Alignment Search Tool (BLAST) with published homologous sequences of flanking sequences of the bar gene in the National Center for Biotechnology Information (NCBI) database (http://www. ncbi.nlm.nih.gov/nuccore/).

\section{RESULTS}

\section{PCR results of each primer}

Figure 3 shows the PCR results with the P1, P2, and P3 single primers for the transgenic and non-transgenic maize. The P1 and P3 single primers did not yield exclusive bands of the transgenic plants. However, the P2 single primer obtained the clear band A. The length of band A (about $900 \mathrm{bp}$ ) was larger than the distance between the P2 primer and the left T-vector border (583 bp), and band A did not appear in the non-transgenic control.

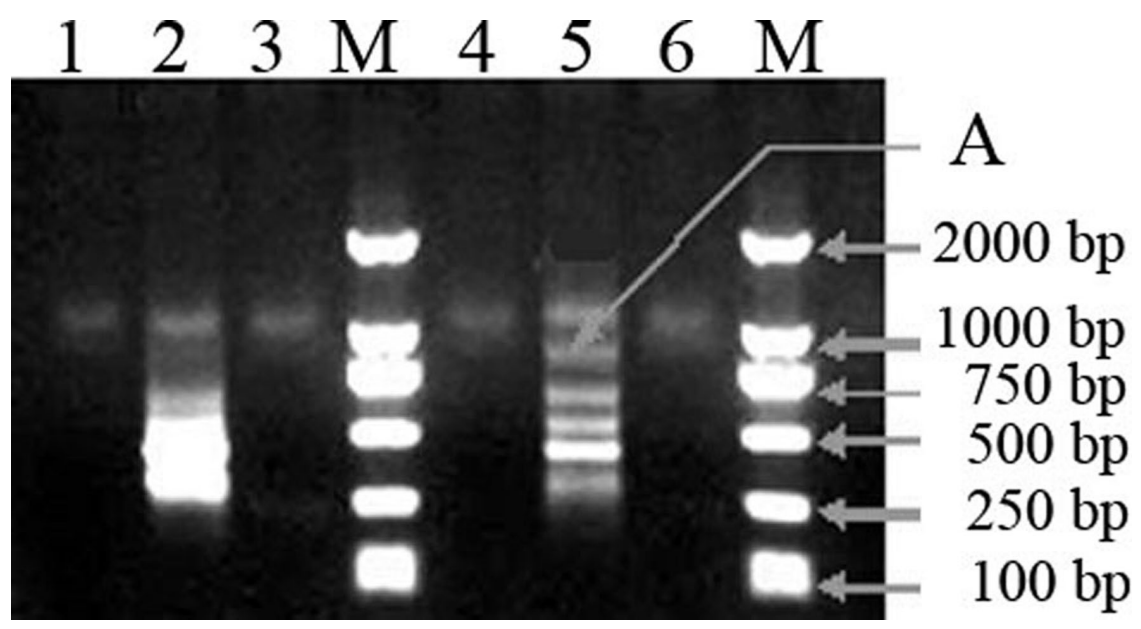

Figure 3. Polymerase chain reaction (PCR) results of each primer for transgenic maize and a non-transgenic control. Lane $M=$ DL2000 marker; lanes 1, 2, and $3=$ PCR products using the P1, P2, and P3 single primers and the non-transgenic control; lanes 4,5 , and $6=\mathrm{PCR}$ products using the $\mathrm{P} 1, \mathrm{P} 2$, and $\mathrm{P} 3$ single primers and the transgenic maize.

\section{Sequencing}

Figure 4 shows the sequencing results of band $\mathrm{A}$. The flanking sequence of the T-DNA insertion site, with a length of $272 \mathrm{bp}$, was determined. By the NCBI BLAST alignment, the sequences in gray color (Figure 4) were homologous to maize AY664415.1. 


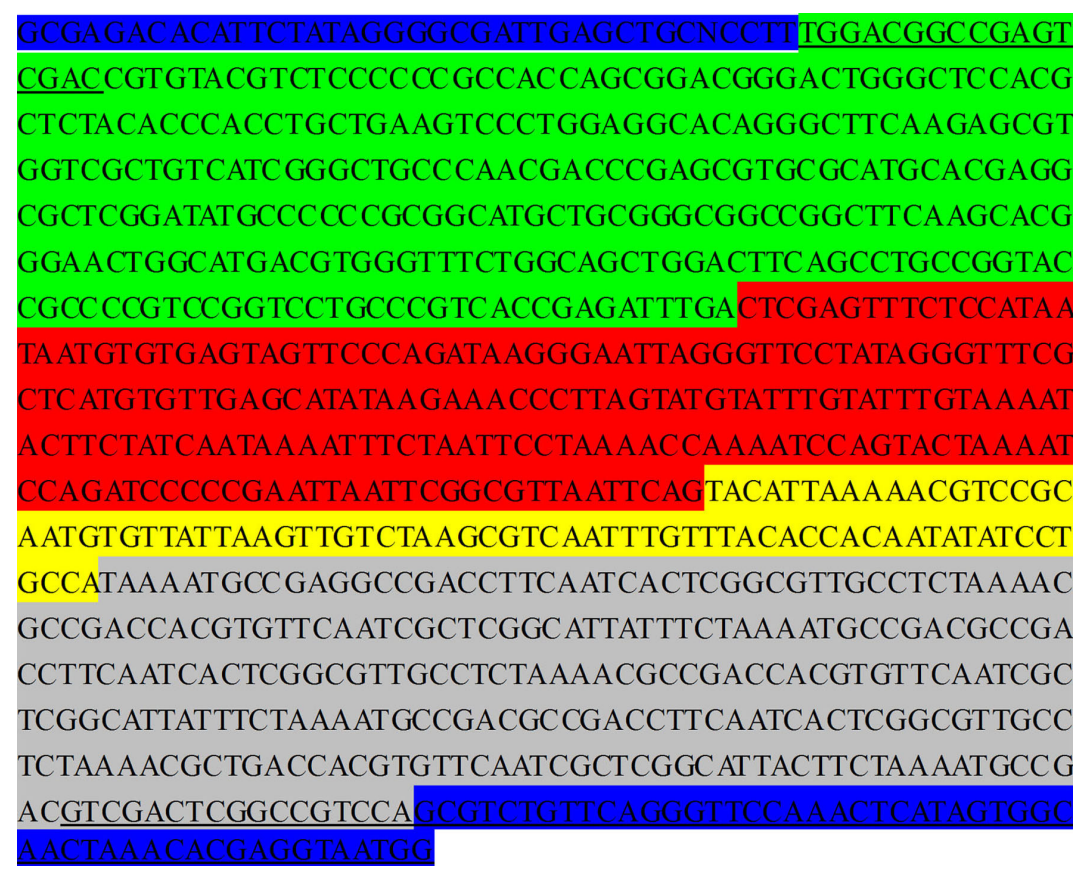

Figure 4. Sequencing results of band A from the $\mathrm{P} 2$ single primer. Blue indicates the $p E A S Y$-Blunt Simple Cloning Vector that was used for sequencing; green indicates the bar gene; red indicates the $35 \mathrm{~S}$ polyA; yellow indicates the left border of the expression T-vector; and gray indicates the cloned flanking sequences.

\section{DISCUSSION}

Determining the integration position of the exogenous gene in the genome of the target plant is an important task in transgenic plant research. Currently, TAIL-PCR is the most commonly used method (Liu and Whittier, 1995; Liu et al., 1995; Song et al., 2005; Liu and Chen, 2007; Liang et al., 2010). However, the primer design of TAIL-PCR is complex, and the PCR procedures are complicated and time-consuming. This study designed single primers with restriction sites of the exogenous gene for single-primer PCR, and the flanking sequence was identified based on the distribution of restriction sites in the plant genome. Three short single primers were designed with the transgenic bar gene as the anchor gene, which was inserted into the transgenic maize genome. A 33-cycle single-primer PCR obtained the flanking sequences of the known gene, the bar gene, in the transgenic maize. With this PCR method, designing the primers was simple, the PCR procedure and operation were simple, and PCR took only $2-3 \mathrm{~h}$. In PCR procedures, 3-6 cycles should be at a low-annealing temperature; the annealing temperature should be equal to or slightly greater than the optimum primer annealing temperature, but the difference should not exceed $3^{\circ} \mathrm{C}$. The subsequent 30 cycles at the high-annealing temperature were sufficient for amplification. The best method was to use the 2-point method for PCR.

Certainly, the genome distribution of restriction sites is different between various species and varieties of the same species. This is just the theoretical basis of amplified fragment length polymorphism. According to the completely random arrangement principle, a 6-bp restriction site should appear once in every 4096 bases in the genome (Antal et al., 2004). In practice, the 
genome distribution of restriction sites does not completely follow the random arrangement principle. Two identical restriction sites may be separated by only a short distance sometimes, but they may be very far away other times. The rearrangement of the different restriction sites is also different after the insertion of a foreign gene. Hence, not all single primers that are designed according to the genome distribution of restriction sites will yield clearly distinguishable PCR products (Ma et al., 2011a,b, 2012). For example, in this study, the P1 and P3 primers did not yield a differential band in the transgenic maize in comparison with the non-transgenic control. Therefore, it is necessary to use a non-transgenic control. The obtained band that is sequenced, with a length that is larger than the distance between the single primer and the left border of the T-vector, should be amplified exclusively in the transgenic plants.

In conclusion, single-primer PCR can be used to obtain the flanking sequences of the T-DNA insertion position based on the distribution of restriction sites in the plant genome. This method excludes the complex primer design and experimental procedures of TAIL-PCR and restriction site extension PCR, and it saves time and money. It is a simple, fast method to determine the flanking sequences of the T-DNA insertion position.

\section{Conflicts of interest}

The authors declare no conflict of interest.

\section{ACKNOWLEDGMENTS}

Talents Program.

\section{REFERENCES}

Antal Z, Rascle C, Fevre M and Bruel C (2004). Single oligonucleotide nested PCR: a rapid method for the isolation of genes and their flanking regions from expressed sequence tags. Curr. Genet. 46: 240-246.

Ji J and Braam J (2010). Restriction site extension PCR: a novel method for high-throughput characterization of tagged DNA fragments and genome walking. PLoS One 5: e10577.

Jones DH and Winistorfer SC (1992). Sequence specific generation of a DNA panhandle permits PCR amplification of unknown flanking DNA. Nucleic Acids Res. 20: 595-600.

Kim YJ, Kwak CI, Gu YY, Hwang IT, et al. (2004). Annealing control primer system for identification of differentially expressed genes on agarose gels. Biotechniques 36: 424-6, 428, 430.

Liang CZ, Zhang R, Sun GQ and Meng ZG (2010). Cloning of stress-related transcription factors gene from cotton by optimized TAIL-PCR. Cotton Sci. 22: 195-201.

Liu YG and Whittier RF (1995). Thermal asymmetric interlaced PCR: automatable amplification and sequencing of insert end fragments from P1 and YAC clones for chromosome walking. Genomics 25: 674-681.

Liu YG and Chen Y (2007). High-efficiency thermal asymmetric interlaced PCR for amplification of unknown flanking sequences. Biotechniques 43: 649-50, 652, 654.

Liu YG, Mitsukawa N, Oosumi T and Whittier RF (1995). Efficient isolation and mapping of Arabidopsis thaliana T-DNA insert junctions by thermal asymmetric interlaced PCR. Plant J. 8: 457-463.

Ma J, Guan SC, Yao D, Wei YF, et al. (2011a). Problems with and a system to eliminate single-primer PCR product contamination in simple sequence repeat molecular marker-assisted selection in soybean. Genet. Mol. Res. 10: 1659-1668.

Ma J, Wang PW, Yao D, Wang YP, et al. (2011b). Single-primer PCR correction: a strategy for false-positive exclusion. Genet. Mol. Res. 10: 150-159.

Ma J, Guan SC, Zhang Z and Wang PW (2012). Single- and double-SSR primer combined analyses in rice. Genet. Mol. Res. 11: 1032-1038.

Song DF, Han N, Bian HW and Zhu MY (2005). Analysis of cbfl flanking sequences in transgenic tobacco by TAIL-PCR. Acta Agron. Sin. 31: 1377-1379. 